\title{
Repair of a werewolf injury: a case of complicated multiple facial lacerations and avulsions
}

\author{
Paul Gerald Caronoñgan Lavarias, MD, MBA \\ Pan Pacific Aesthetic Institute, Makati, Philippines
}

\begin{abstract}
Traumatic lacerations are skin incisions that are accidental. Their depth can affect nerves, blood vessels, salivary glands, and bone. Avulsions, on the other hand, are caused by shearing forces, and the depth of injury goes beyond the papillary dermis into deeper structures. Avulsions involve a huge amount of torn tissue, thereby leaving voids. Facial lacerations and avulsions are commonly caused by vehicular accidents, according to the statistics. In a study conducted by the Philippine Statistics Authority, approximately 3,000 people aged 20 to 30 years old are involved in vehicular accidents. Data from the Land Transportation Office showed that $69 \%$ of the vehicles involved in vehicular accidents are motorcycles.
\end{abstract}

Keywords: avulsions; cosmetic surgery; reconstructive surgery; shearing forces; skin incisions; traumatic lacerations

\section{Introduction}

Traumatic lacerations are skin incisions that are accidental. Their depth can affect nerves, blood vessels, salivary glands, and bone. Avulsions, on the other hand, are caused by shearing forces, and the depth of injury goes beyond the papillary dermis into deeper structures [1]. Avulsions involve a huge amount of torn tissue, thereby leaving voids [1]. Facial lacerations and avulsions are commonly caused by vehicular accidents, according to the statistics. In a study conducted by the Philippine Statistics Authority, approximately 3,000 people aged 20 to 30 years old are involved in vehicular accidents [2]. Data from the Land Transportation Office showed that $69 \%$ of the vehicles involved in vehicular accidents are motorcycles [2].

\section{Case report}

A 27-year-old man from Antipolo City, Philippines, was ad- mitted for multiple facial lacerations and avulsions. He was involved in a motor vehicular accident wherein he allegedly rode his motorcycle without a helmet in an intoxicated state. He hit a gutter and flew off his vehicle, hitting his face on multiple tree branches.

The patient was awake, coherent, Glasgow Coma Scale 15, and showed stable vital signs during physical examination. He sustained gross, avulsed facial wounds, extending from the right melolabial fold to the right nasofacial groove, nasion, right ala, supratip, and nasal tip as well as lacerated wounds extending from the subnasale to the left melolabial fold. Assessment of the facial nerve revealed a House-Brackmann grade of III. The forehead showed moderate movement, complete eye closure was observed, and motion of the mouth was slightly weak (Fig. 1).

The wounds were cleaned with copious irrigation using dilute hydrogen peroxide wash to remove foreign bodies from the wound. The wounds and facial area were sterilized with povidone-iodine antiseptic solution. Local anesthesia consist-

Received May 29, 2020; Revised Jun 16, 2020; Accepted July 11, 2020

Corresponding author: Paul Gerald Caronoñgan Lavarias

E-mail: paul.gerald.lavarias@gmail.com

This is an Open Access article distributed under the terms of the Creative Commons Attribution Non-Commercial License (http://creativecommons.org/licenses/by-nc/4.0), which permits unrestricted non-commercial use, distribution, and reproduction in any medium, provided the original work is properly cited.

Copyright ( 2020 Korean Society of Korean Cosmetic Surgery and Medicine (KSKCS \& KCCS). 

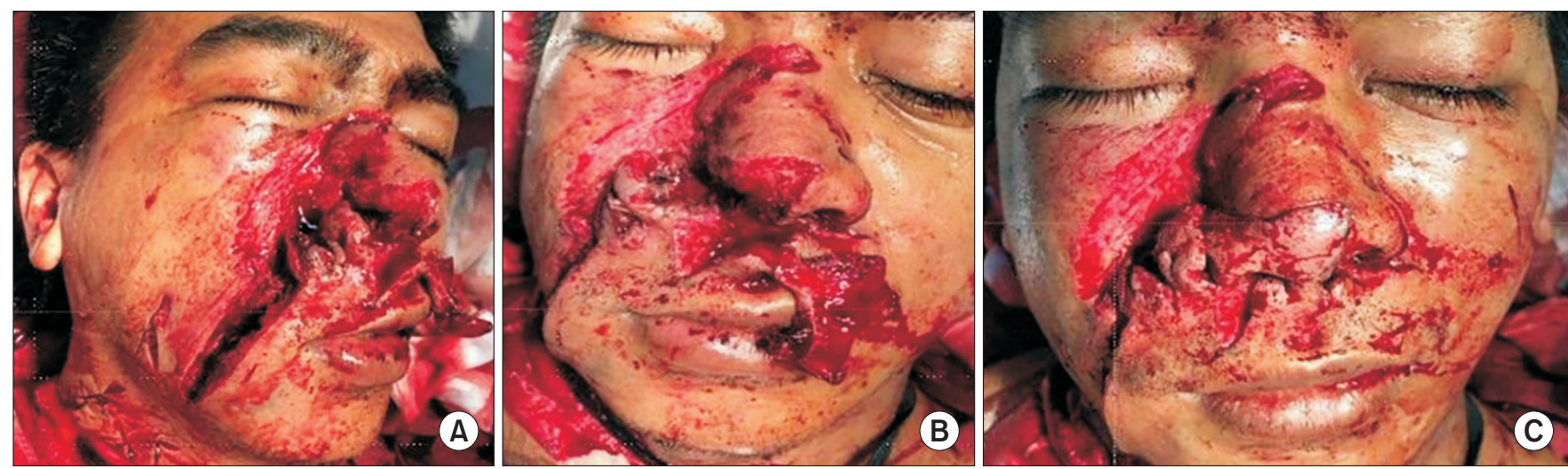

Fig. 1. (A) Oblique view showing: avulsed wounds of the nasion, right ala, supratip, and tip and columella, and right melolabial fold, extending to the right nasofacial groove, and the lacerated wound of the lateral cheek and left subnasale, extending to the left melolabial fold. (B) Frontal view showing the same avulsed and lacerated wounds shown in the oblique view. (C) Frontal view after fixing the parts of the face in place.
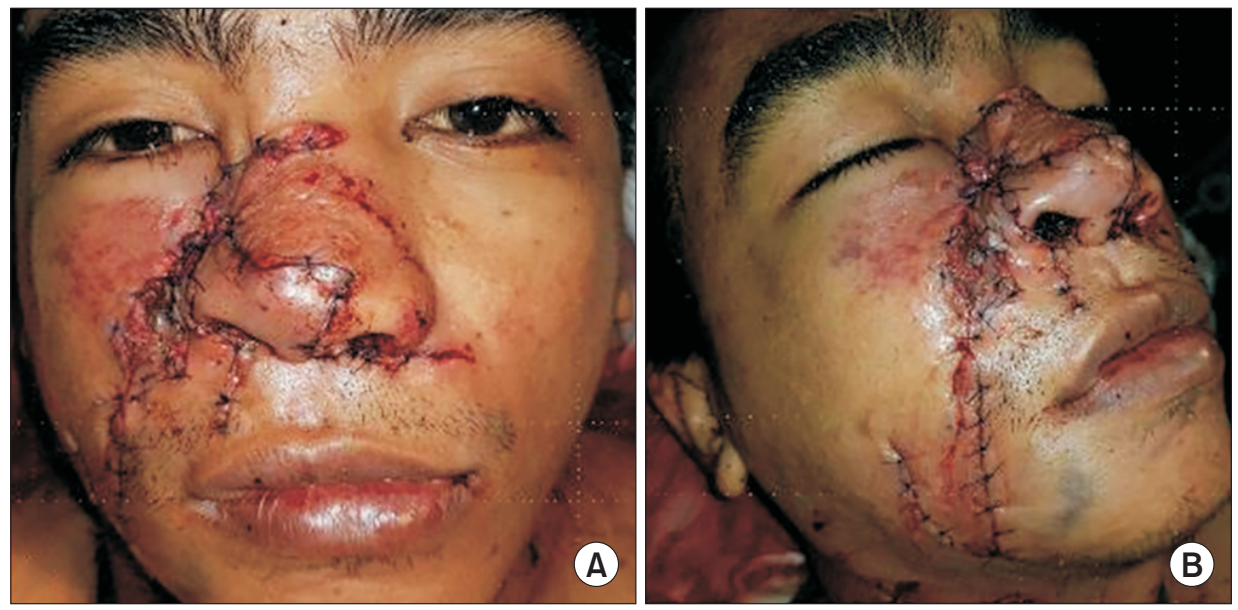

Fig. 2. (A) Frontal view showing the repaired nasion, right nasofacial groove, right melolabial fold, right nasal ala, supratip, nasal tip, columella, subnasale, and left melolabial fold. (B) Oblique view showing the repaired right nasofacial groove, right melolabial fold, right nasal ala, and right lateral upper lip subunit.

ing of $2 \%$ lidocaine with 1:100,000 epinephrine was infiltrated into the wounds. Necrotic wound edges were trimmed using iris scissors. The melolabial area was repaired in layers. The muscle and subcutaneous tissue were reapproximated with 4-0 catgut sutures using the inverted-T technique. The skin was closed with a 4-0 Prolene suture using the vertical mattress and simple interrupted stitching techniques. Next, the right nasofacial groove was repaired using the layer closure method. The muscles and subcutaneous layer were reapproximated using 4-0 catgut sutures, while the skin was repaired using 4-0 Prolene sutures with a simple interrupted technique. The nasion was also repaired using 4-0 Prolene sutures with a simple interrupted technique. The right nasal vestibule was repaired in layers, from the mucosa to the muscular layer, using 4-0 catgut sutures. Lastly, the skin of the right nasal ala, supratip, and tip were repaired using 4-0 Prolene sutures, with the simple interrupted technique (Fig. 2).

Postoperatively, reassessment of the patient's facial nerve received a House-Brackmann grade of III. The patient was sent home with the following: clindamycin (500 mg) tablets, to be taken every 6 hours for 7 days; mefenamic acid (500 mg) tablets for pain, to be taken every 6 hours; prednisone $(20 \mathrm{mg}$ ) tablets for the facial nerve, to be taken every 8 hours; and sodium chloride nasal spray, with 3 sprays per nostril to be performed hourly for 7 days. The patient was advised to perform daily wound care.

One week postoperatively, sutures were removed. Immature scars were evident at the right melolabial fold, nasofacial groove, nasion, columella, ala, ala base, nasal tip, and at the left melolabial fold. The patient was advised to undergo rehabilitation therapy for the paralysis of the marginal mandibular branch of the facial nerve, as shown by the slight drooping of the right corner of the mouth (Fig. 2).

\section{Discussion}

The patient underwent immediate repair of his wounds to 
mitigate the risk of soft tissue swelling, as this can obscure landmarks and make primary closure difficult. An additional goal of immediate repair was to decrease exposure of the wound to bacterial infections. Studies show that wound closure should ideally take place during the first 8 hours of injury [3].

The goals of treatment for lacerations are appropriate reapproximation of deep tissue, reapproximation of the dermis with tension-free closure, and precise apposition of the epidermal edge [4]. Most of the avulsed wounds were repaired with primary closure due to a well-preserved pedicle, while some underwent undermining due to full thickness skin loss, thereby preventing excessive tension [1].

In this case, 4- 0 catgut sutures were used in the subcutaneous layer to obliterate dead space, prevent fluid accumulation, and relieve tension from the skin edges [1].

Skin closure of the lacerated and avulsed wounds was performed with the eversion technique. As healing scars contract and invert, they cause a shadow that is easily noticeable. Thus, the use of vertical mattress sutures best everts the repaired wounds, thereby elevating the incisions that reverse scar contracture [4].

On follow-up, the patient had immature scars (Fig. 3). By appearance, immature scars are red, slightly pruritic, and painful compared to mature scars, which are light-colored and flat [5]. Immature scars can develop into hypertrophic scars after approximately 1 month [5].

The treatment objective for this patient is to prevent immature scars from turning into hypertrophic scars. The plan for the patient is for him to undergo silicone therapy for 6 months. If the scars are still present, he will undergo adjuvant intralesional steroid therapy for 4 weeks until the scar flattens [6]. After this treatment, the remaining scars will be corrected with a Z- or Wplasty depending on their appearance and location.

Silicone therapy can be performed using either silicone gel or silicone sheet. Silicone sheet is the recommended first-line treatment, but silicone gel is easier to use [7]. Silicone therapy provides the stratum corneum with maximal occlusion and hydration, decreases transepidermal water loss and cytokinemediated signaling from keratinocytes, and gently reduces tension [7]. It must be worn for 12 consecutive hours a day for 6 to 12 months to get optimal results [5,7].

Intralesional corticosteroids are administered for 2 to 4 weeks until the scars flatten. Research shows that triamcinolone acetonide $(10-40 \mathrm{mg} / \mathrm{ml})$ is effective when injected into the papillary dermis [6]. It has anti-inflammatory, immunosuppressive, and vasoconstrictive effects [7]. In scars, it inhibits keratinocyte
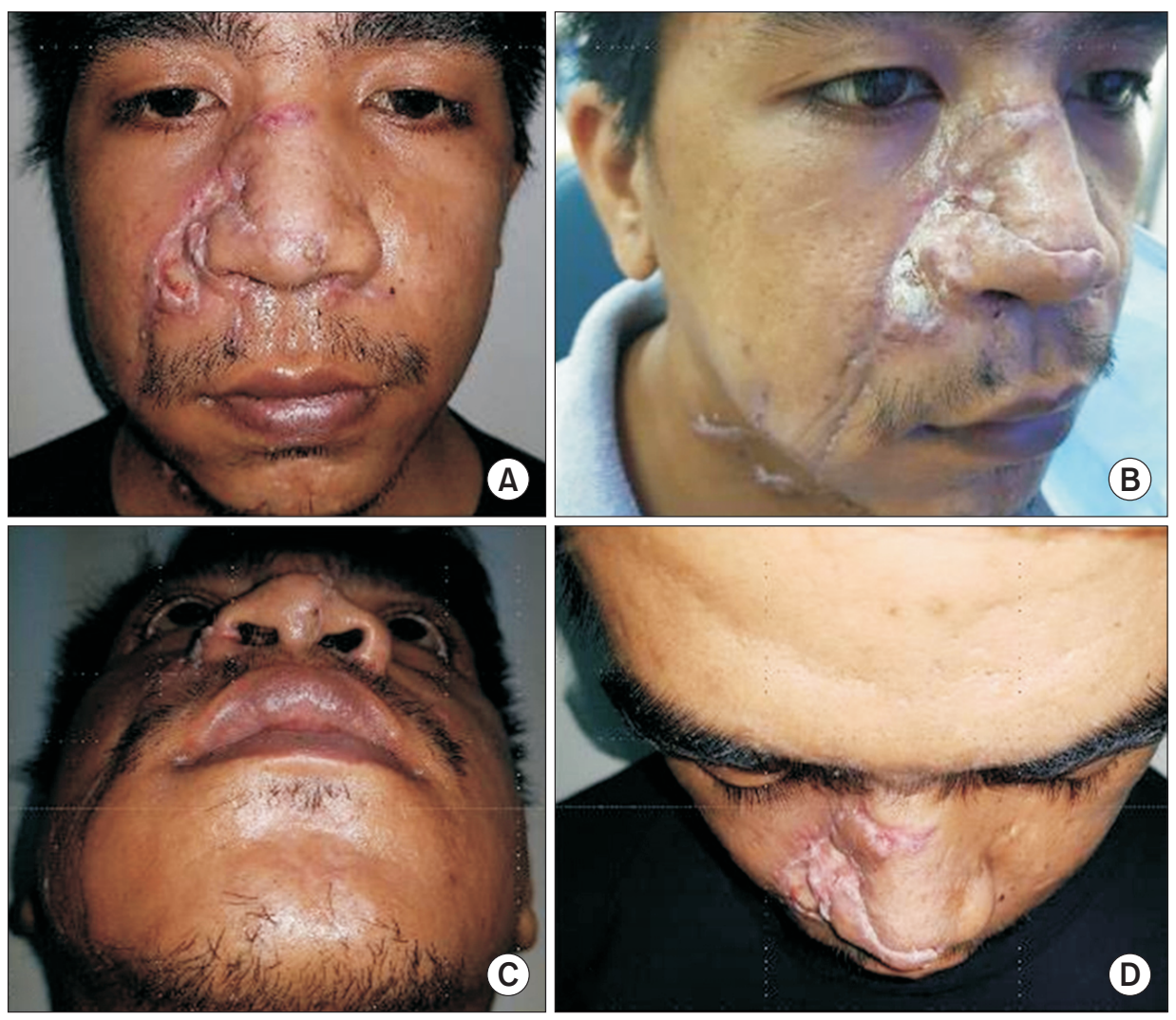

Fig. 3. (A) Postoperative frontal view showing immature scars of nasion, right nasofrontal area, right melolabial fold, right nasal ala, supratip, tip, and upper lip subunits. (B) Oblique view of immature scars as seen from the frontal view, with lateral subunit of right lower cheek. (C) Worm's view of immature scars on the right nasal ala and columella. (D) Immature scars on the nasion, right nasofrontal area, right nasal ala, supratip, and tip. 


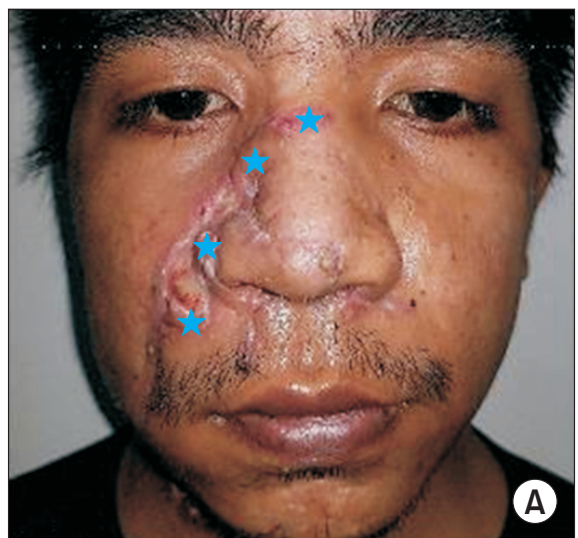

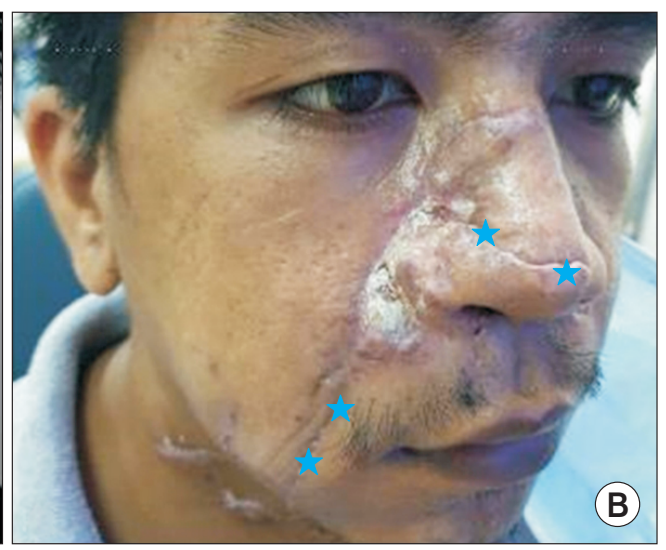

Fig. 4. Marked with stars are the targets for the intralesional corticosteroid therapy: (A) frontal view showing the target at melolabial fold, nasofacial fold, nasion; (B) oblique view showing the target at melolabial fold, bilateral nasal ala, supratip, left columella, nasal tip . and fibroblast proliferation as well as glycosaminoglycan synthesis, and decreases matrix metalloproteinases [7]. Possible sites for intralesional steroids for the patient include the skin at the right body of the mandible, the right melolabial area, the right nasofacial area, the right ala, the supratip, the left nasal ala, the left columella, the nasal tip, and the nasion (Fig. 4).

If the scars are persistent for more than 1 year of silicone therapy and intralesional corticosteroid use, tension-releasing surgical scar revision, Z-, and W-plasty are indicated [6]. Both $\mathrm{Z}$ - and W-plasty act via the mechanism of disturbing the circle upon which the scar pulls. They thicken the scar due to persistent stimulation of extracellular matrix production [7].

In this case, Z-plasty is indicated for scars greater than $30^{\circ}$ away from, the relaxing skin tension line and contracted scars [8]. In the design of the Z-plasty, the ideal angle is $60^{\circ}$, with both peripheral limbs equal in length to each other and to the central limb [8]. The multiple and different vectors of tension of the Zplasty prevent scar contracture and widening [8].

$\mathrm{W}$-plasty will be used in the patient so that his linear scars become irregular, such that the majority of the limbs fall along the relaxed skin tension line [8]. It is indicated for the scars that run across the relaxed skin tension line as well as the scars on curved surfaces such as the nasion [8]. The terminal portion of the $\mathrm{W}$-plasty is such that there is a $30^{\circ}$ angle at that end [8].

The overall goal for this patient is to restore his prior appearance following his unfortunate accident. If full restoration is not possible, the doctors involved in his treatment can nonetheless be considered to have tried their best in helping him achieve the best aesthetic appearance possible with what is left of his face. There are, of course, other techniques and methods for scar management as well. Doctors should not be afraid to explore other avenues and to innovate when treating their patients.

\section{Conflicts of interest}

The author has nothing to disclose.

\section{References}

1. Carron MA. Soft tissue trauma. In: Mathog RH, Carron MA, Shibuya TY, editors. Mathog's atlas of craniofacial trauma. 2nd ed. Philadelphia: Lippincott Williams \& Wilkins; 2012. p. 59-64.

2. Sy K. In numbers: road crash incidents in the Philippines [Internet]. Pasig City: Rappler Inc.; c2017 [cited 2020 Jan 8]. Available from: https://rappler.com/moveph/advocacies/roadcrashes-philippines-awareness-safety.

3. Kretlow JD, McKnight AJ, Izaddoost SA. Facial soft tissue trauma. Semin Plast Surg 2010;24:348-56.

4. Hill JD, Hamilton GS 3rd. Facial trauma: soft tissue lacerations and burns. In: Flint PW, Haughey BH, Lund VJ, Niparko JK, Robbins KT, Thomas JR, et al., editors. Cummings otolaryngology: head and neck surgery. 6th eds. Philadelphia: Saunders; 2015. p. 310-3

5. Al-Shaqsi S, Al-Bulushi T. Cutaneous scar prevention and management: overview of current therapies. Sultan Qaboos Univ Med J 2016;16:e3-8.

6. Monstrey S, Middelkoop E, Vranckx JJ, Bassetto F, Ziegler UE, Meaume S, et al. Updated scar management practical guidelines: non-invasive and invasive measures. J Plast Reconstr Aesthet Surg 2014;67:1017-25.

7. Mokos ZB, Jović A, Grgurević L, Dumić-Čule I, Kostović K, Čeović R, et al. Current therapeutic approach to hypertrophic scars. Front Med (Lausanne) 2017;4:83

8. Sharma M, Wakure A. Scar revision. Indian J Plast Surg 2013;46:408-18. 